\title{
Las vidrieras medievales conservadas de la Catedral de Valencia
}

\author{
Carmela Falomir Ventura
}

Desde que a comienzos de nuestro siglo, don José Sanchís Sivera nos diera a conocer tanto los testimonios documentales como arqueológicos conservados en la Catedral de Valencia sobre el arte de la vidriería y sus artífices, no se ha llegado a publicar nada nuevo al respecto. Es por ello importante dar un paso más allá de lo que el propio Sanchís Sivera dejó ya dicho de que en la Seo valentina hubo grandes vitrales historiados durante la Edad Media y siglos posteriores, llegando a tener gran actividad aquellos hombres cuyo oficio de maestros de vidrieras les hacían estar en continuo contacto con la divinidad, con la luz.

Sí, en parte quedó ya constatado, pero en éste inicial estudio deseamos dar a conocer un testimonio más de lo que todavía hoy puede ofrecernos la Catedral de Valencia respecto a los vitrales que en su día articularon simbólica y lumínicamente su interior. Así durante años junto con la conservación de las piezas de vidrio que componían el pequeño rosetón que presentó Sanchís Sivera en sus obras ${ }^{1}$, en el archivo se conservaron otras tantas piezas recogidas durante la restauración que se realizó al magnífico rosetón, llamado Salamó, de la Puerta de los Apóstoles a finales de los años cincuenta y principios de los sesenta, y aunque éstas sean escasas son una muestra viva de lo que debió de tener la Seo antes de la llegada del reformador neoclasicismo del siglo XVIII.

A continuación mostramos aquellas piezas más interesantes que en su día debieron de formar parte de una composición mucho más compleja e importante.

1 SANChís I SiVERA, José, La Catedral de Valencia. Guía histórica y artística, Valencia, 1909. Y en su artículo "Vidriera historiada medieval en la Catedral de Valencia», en la revista Archivo de Arte Valenciano, tomo IV, 1918, págs. 23-24. 
En primer lugar, quisiera hacer mención especial a la pieza dada a conocer por Sanchís Sivera, la cual se conserva cuidadosamente guardada en el archivo catedralicio e incluso cabría añadir otras tres pequeñas piezas de vidrio que completan un poco más esta pequeña roseta: un vidrio rojo sin decoración y dos vidrios verdes con decoración vegetal. El diámetro de ésta pieza es de $24 \mathrm{~cm}$ (fig. 1).

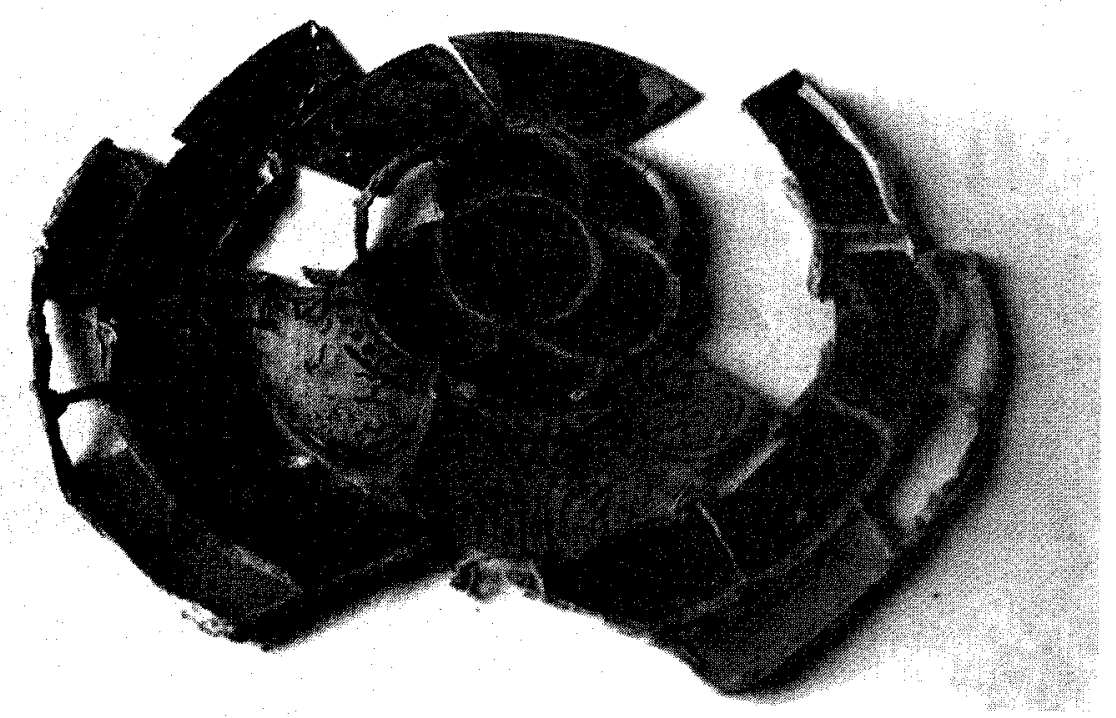

Fig. 1

Como podemos apreciar la vidriera está formando un pequeño rosetón que debió formar parte del Salamó de la catedral, decoradas todas ellas con motivos vegetales excepto los vidrios rojos circundantes y los incoloros del exterior.

La ornamentación vegetal está pintada con grisalla de color ocre delimitando a modo de negativo el motivo representado. La grisalla se encuentra en buen estado de conservación en casi todos los vidrios, en otros en parte ha saltado por completo, como se puede ver en un vidrio incoloro donde las hojas de vid casi han desaparecido y en uno de los vidrios azules (fig. 2) (donde incluso está afectada la superficie del vidrio). El resto está en buen estado de conservación a pesar de la suciedad que presenta la superficie de los vidrios. Sin embargo el emplome está en mal estado y ha desaparecido en gran parte, conservándose la pieza central y los laterales. Para acabar hemos de añadir que en ella se combinan 
vidrios de colores que van desde el rojo plaqué hasta el azul pasando por el amarillo, verde y el incoloro?

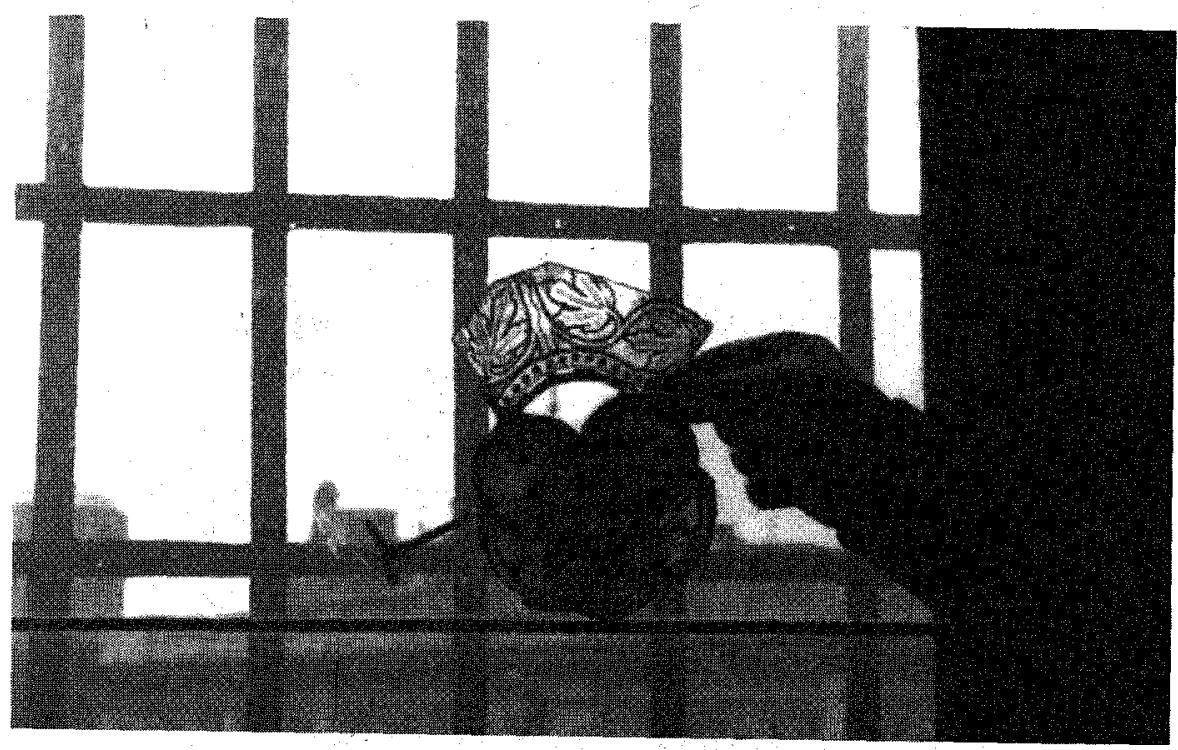

Fig. 2

En segundo lugar hemos localizado en el archivo catedralicio otras tantas piezas fragmentadas que se guardan cuidadosamente:

A) El centro de una roseta cuatrilobulada, de vidrio amarillo en el centro y con motivo de hojas, y los cuatro lóbulos de vidrio verde que rodean la pieza central, después un vidrio granate rodea la composición (fig. 3).

B) Otra pieza igual a la anterior con el mismo motivo vegetal, pero está menos completa, los vidrios granate no se encuentran sujetos al emplome (fig. 4).

2 Quisiéramos apuntar respecto a estos vidrios incoloros que lo son completamente, lo que nos hace suponer que podría tratarse de piezas recompuestas posteriormente. SANCHIS SIVERA data esta pieza en el siglo xV, siglo en que el Salamó fue en varias ocasiones adobado como consta en la documentación y claro está también lo sería en todas las épocas. También cabría barajar la hipótesis de que al ser Valencia un territorio donde el vidrio dominante no es de composición potásica como ocurre en las zonas interiores de la Península, pudiera tratarse de un vidrio de finales del XV cuando la técnica de fabricar vidrio incoloro estaba más perfeccionada. $\mathrm{El}$ contacto que tenía Valencia con Italia y con la propia Venecia pudieron ser causas de su aparición aunque un análisis químico de estas piezas nos permitiría conocer realmente su datación más exacta. 
CARMELA FALOMIR VENTURA

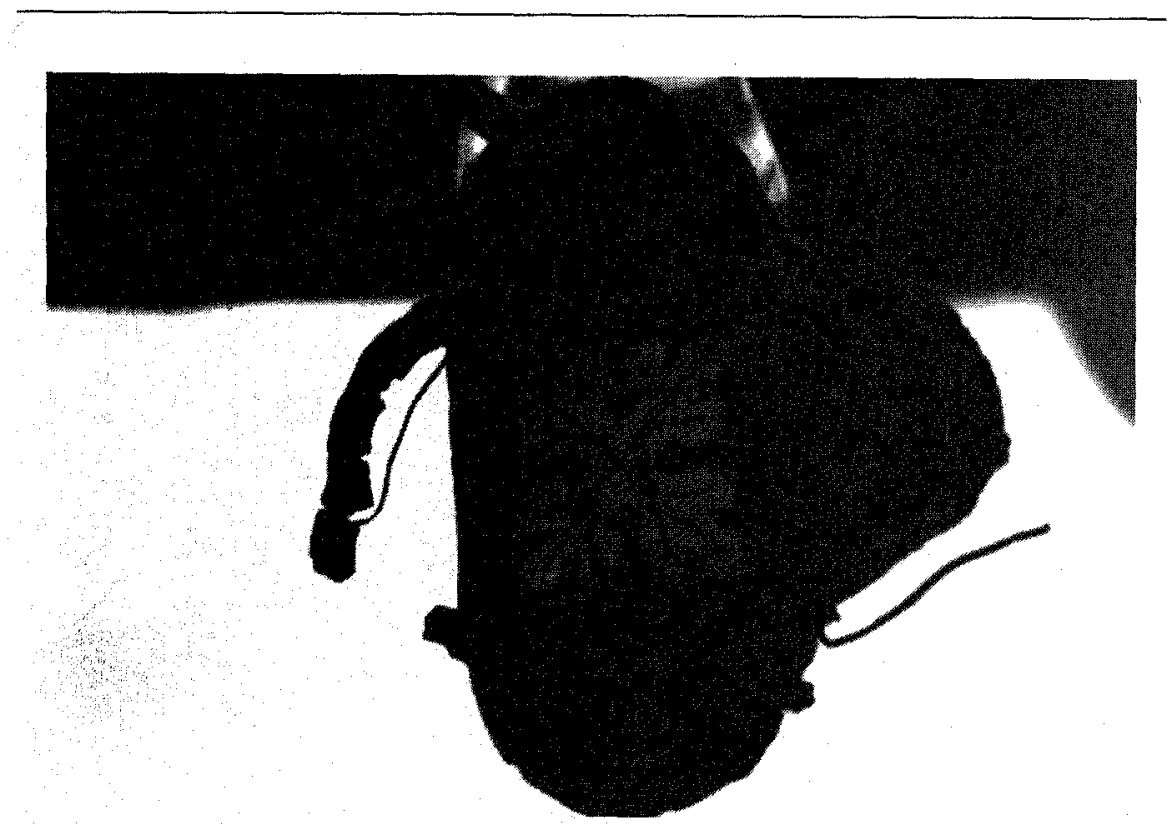

Fig. 3

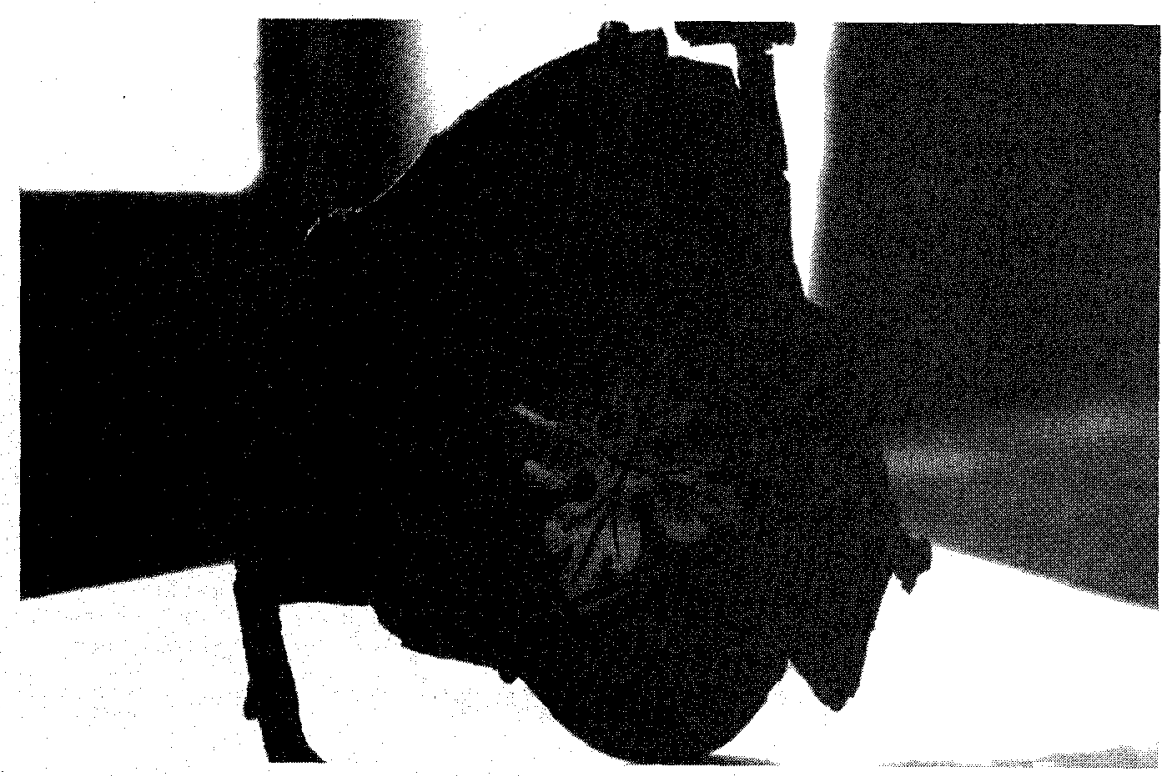

Fig. 4 
C) Otra pieza igual a las dos anteriores pero más fragmentada en cuanto a la pieza central conservándose dos vidrios de color verde y uno fragmentado, parte de ella está rodeada por un vidrio de color granate (fig. 5).

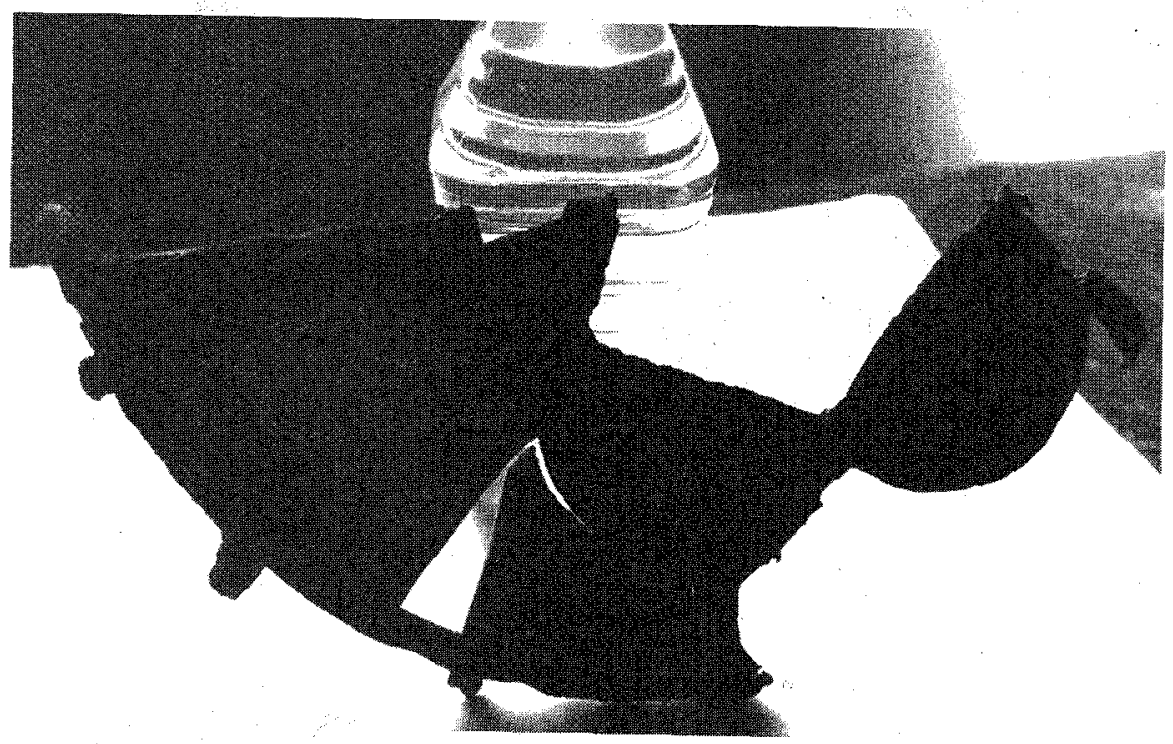

Fig. 5

Todo ello nos hace suponer que estas piezas debieron de estar juntas en la misma vidriera junto con otros vidrios de colores que se encuentran sueltos y sin ninguna conexión por su estado fragmentario y que conforme se vaya avanzando en el estudio de esta investigación se logrará una visión del conjunto más amplia.

Las siguientes piezas de vidrio son una selección de las que se encuentran decoradas con grisalla:

A) Pieza de vidrio azul cobalto, con un motivo vegetal de tres flores, es, a pesar de su sencillez, muy hermosa destacando a parte de su motivo ornamental la ondulación sinuosa que presenta la superficie del vidrio dando así testimonio del trabajo artesanal en cilindro por el que fue realizada (fig. 6).

B) Pieza de vidrio rosa oscuro cuyo motivo vegetal es semejante al anterior por el gran parecido que presentan las flores que en ella hay representadas, la pieza está fragmentada (fig. 7). 
CARMELA FALOMIR VENTURA

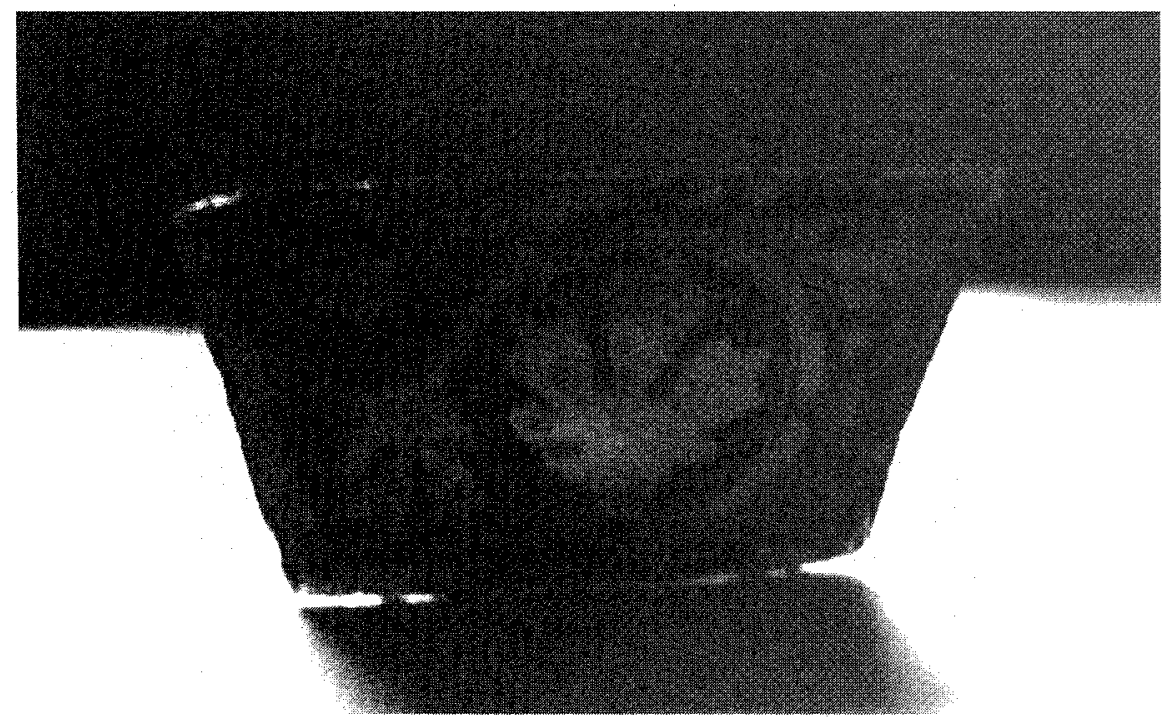

Fig. 6

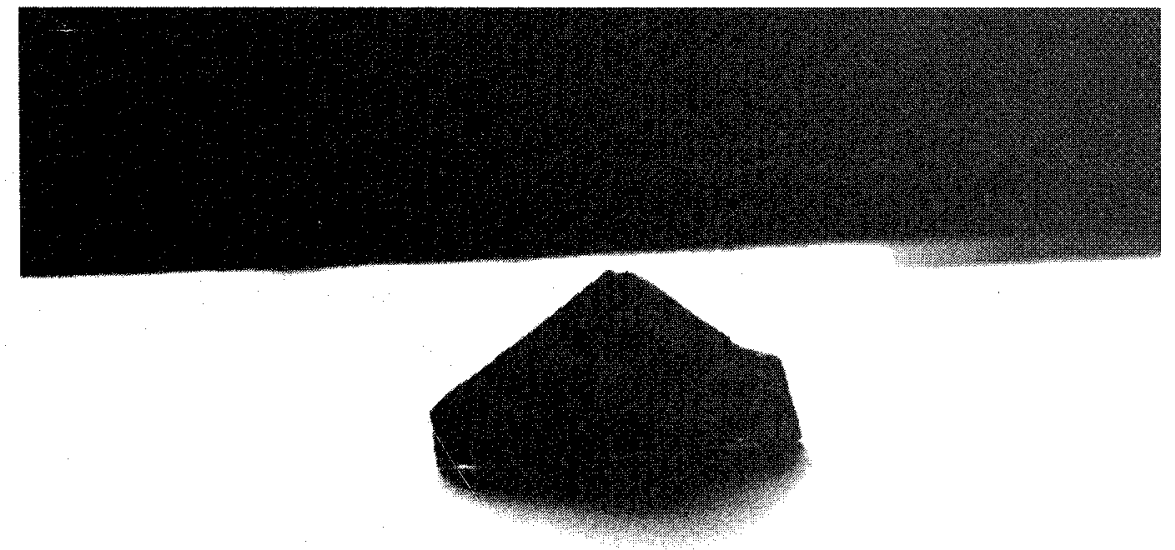

Fig. 7 
C) Pieza de color rosa claro fragmentada también presenta restos de decoración de grisalla no se sabe exactamente el motivo que se ilustraría aunque parecen ser hojas lanceoladas (fig. 8).

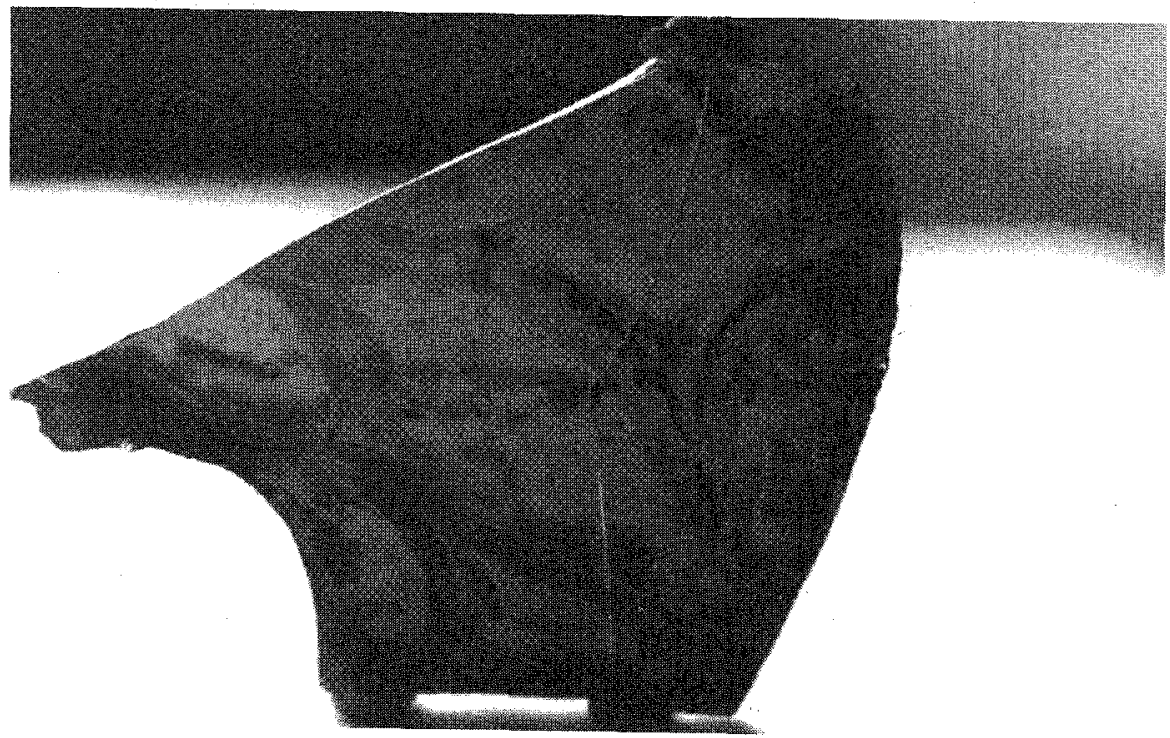

Fig. 8

Debemos añadir también que hay otra pieza de vidrio del mismo color del anterior, en parte sujetado por restos de plomo y en el que una parte del vidrio se encuentra surcado por líneas verticales. Quizás ambas formaran parte del mismo conjunto ya que la grisalla presenta una pincelada de una tonalidad más clara debajo del trazo más fuerte y más oscuro, se produce ya un intento de búsqueda de volumen ${ }^{3}$ (foto 9 ).

En tercer lugar, presentamos una pieza de extraordinaria belleza se trata de una pequeña roseta de un gran valor porque su presencia demuestra que no tan sólo había representación de motivos vegetales en las vidrieras, sino que lo figurado también tenía un gran protagonismo. Ya Sanchís Sivera

3 Quizás todas estas piezas también se remonten al siglo $\mathrm{xV}$, todo su trabajo artesanal se puede comprobar a simple vista ya que tanto la ciba como el cilindro dejaron sus marcas en la superficie del vidrio, junto con los colores y los motivos vegetales representados. 
CARMELA FALOMIR VENTURA

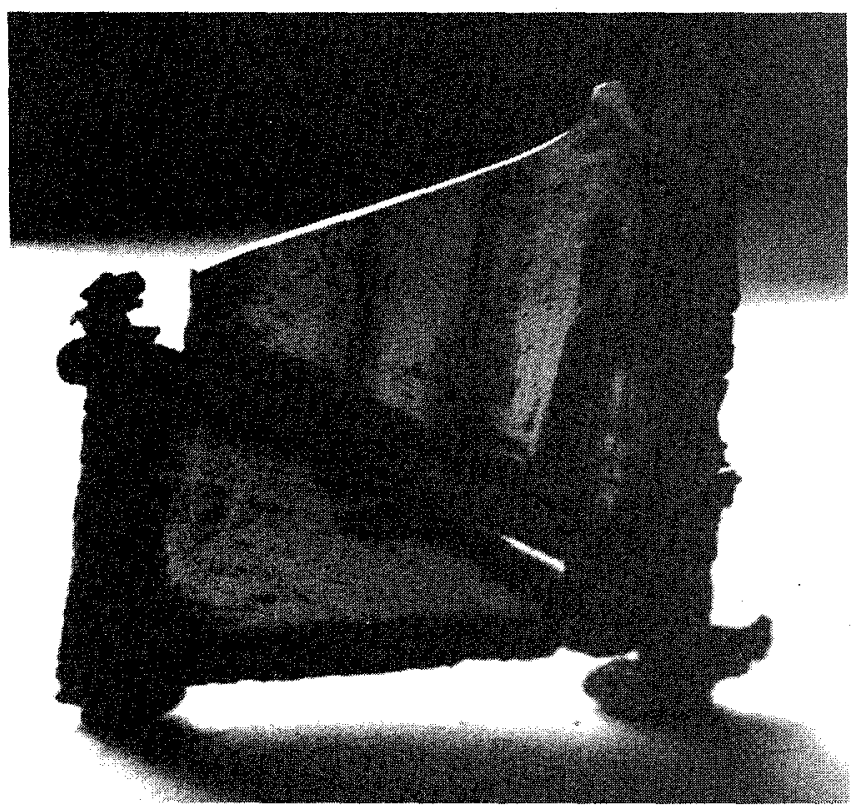

Fig. 9

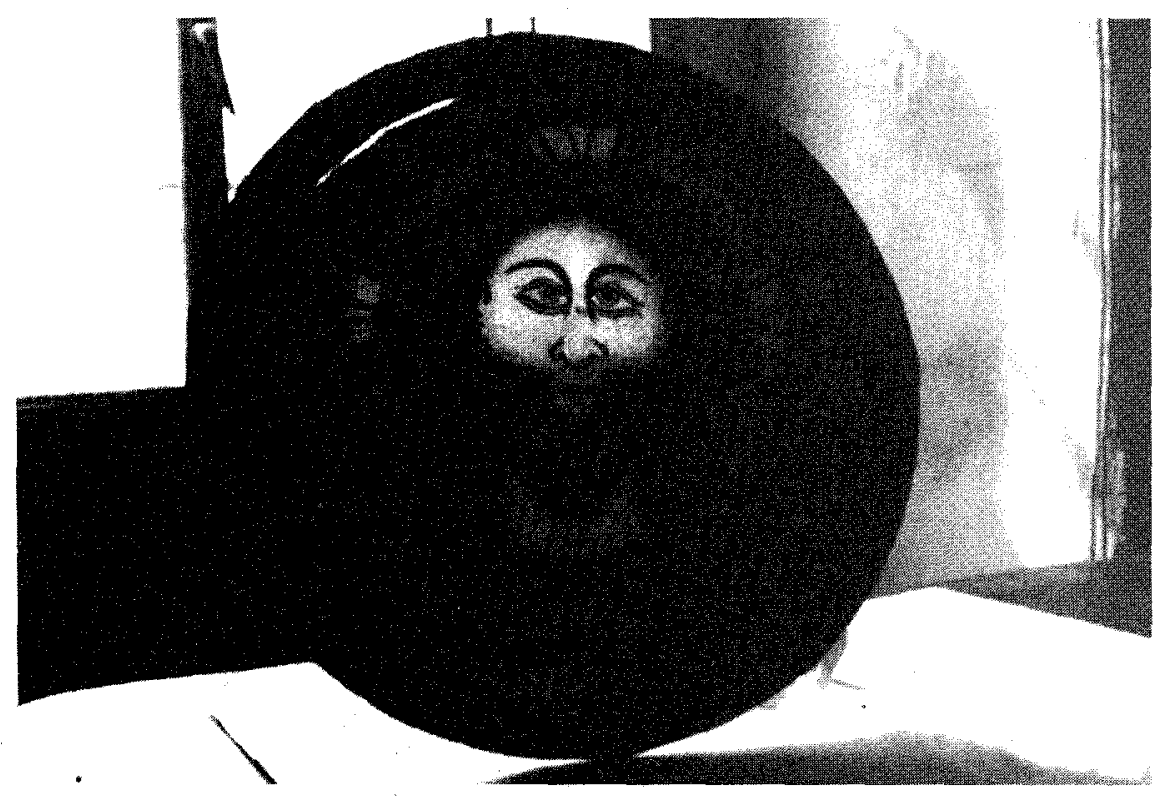

Fig. 10 
lo demostró por medio de la aportación documental pero en cuanto a restos con figuración humana no se conocía nada al respecto ${ }^{4}$ (fig. 10).

En ella se representa el rostro de Cristo, ese rostro que ya desde la época de las catacumbas ha fascinado a todos los artistas. Aparece el busto de Cristo de frente con cabellos hasta los hombros, barbado y con el aurea coronando su cabeza resaltando con vidrio amarillo los rayos que simbolizan su condición de divinidad (formando una cruz), también se aprecia una parte de la túnica de vidrio amarillo. Todo él sobre fondo neutro azul que simboliza el cielo.

Los trazos en grisalla son firmes y delimitan el dintorno de la figura ya que del contorno se encarga el propio emplome intentando reproducir a través de la línea y mediante un lenguaje convencional los rasgos esenciales del rostro, los cabellos..., siendo el resultado un tanto hierático por su actitud frontal y la disposición simétrica pero lleno de expresividad.

También se aprecia la falta de volumen, se omite el claroscuro, no hay tonalidades ni en la cara ni en el cuello tan solo las líneas señalan los pliegues intentando crear bulto, sin embargo la figura queda plana, bidimensional que a su vez contrasta con el cromatismo brillante y luminoso de cada uno de los vidrios utilizados para la composición (rojos, azules...) y unido a la transparencia de éstos se crea toda una simbología de la luz en la cabeza de Cristo.

En cuanto al estado de conservación los vidrios se encuentran en un buen estado en general presentando suciedad en sus dos superficies a causa del polvo acumulado. Se aprecian roturas en dos de los vidrios, una en el cuello a la derecha y otra en un vidrio azul de la izquierda. Con respecto al emplome es aquí donde se presenta la parte más afectada ya que está abombada la parte superior de la izquierda quedando totalmente separada del arco de sujección. El hecho de que el emplome tenga forma de $\mathrm{H}$ junto con la presencia de vidrios rotos que parecen haber sido emplomados posteriormente (como el del pelo a la derecha y parte de los vidrios azules), nos hace suponer que esta pieza ha sido reparada en alguna ocasión.

Comentaríamos por último que los vidrios presentan muchas burbujas y destaca sobre todo la que está justo en el centro de la nariz la cual en superficie está abierta.

4 El chantre de la catedral D. VICENTE CASTELL recogió esta pieza tras ser desmontado el Salamó, entregándola al archivo de la catedral como pieza de inestimable valor. No habiendo sido estudiada anteriormente. 
Después de este análisis y teniendo en cuenta que la Puerta de los Apóstoles de la Seo valentina consta documentalmente que ya se estaba realizando en el año 1303 (1262 se colocaba la primera piedra siendo el maestro de obras Arnaldo Vidal) por el maestro borgoñón Nicolás de Ancona (quien traza y dispone también las naves laterales, el cimborrio, el viejo campanario) atestiguando otros documentos que en el año 1354 ya estaba terminada; se sabe que Nicolás de Ancona estaba rodeado y ayudado por un grupo de escultores y de vidrieros que fueron puestos por el Cabildo de la catedral a su servicio. Todo esto nos lleva a pensar que esta pieza quizás pudiera datarse hacia principios del siglo xIV que junto con la calidad del vidrio y por sus características formales y estilísticas son propias de un gótico lineal donde la influencia del románico y del bizantinismo están todavía presentes en todas las artes.

Si esta pieza fuera original de la época que comentamos tendríamos ante nosotros un testimonio que aunque pequeño en comparación al resto de las grandes vidrieras que aún hoy se conservan en catedrales españolas como Toledo, Sevilla, León... nos permite entrever una parte de lo que supuso este arte de la vidriera en la catedral valenciana. Una catedral que es como un ser vivo que va creciendo, evolucionando a lo largo de los siglos conforme evoluciona el hombre, sin eliminar los testimonios donde uno pueda agarrarse para poder conocer aquello que en su día significó para nuestros antepasados de los siglos XIV y XV. 